\title{
VALUASI EKONOMI KAWASAN ARBORETUM DIPTEROCARPACEAE UNIVERSITAS LANCANG KUNING
}

\author{
Emy Sadjati ${ }^{1}$, Dedi Zargustin², Muhammad Ikhwan' \\ ${ }^{1}$ Staf pengajar Fakultas Kehutanan Universitas Lancang Kuning \\ 2Staf pengajar di Fakultas Pertanian, Universitas Lancang Kuning \\ Jln. Yos Sudarso Km.8 Rumbai Pekanbaru Riau \\ Telp./Fax. (0761) 54092 \\ Email : emy_mnhunilak@yahoo.co.id, dedizargustin@yahoo.co.id, \\ mmighwan@yahoo.com
}

\begin{abstract}
Arboretum as one example of ecosystems that have the diversity of flora and fauna requires good management, so as to provide benefits to the surrounding environment. Biological diversity (biodiversity) that exist in the Arboretum area is quite high. This is because the Arboretum has many species which are usually brought in from outside, then planted and maintained as a collection of plants for various purposes of academic activities, in addition to local species that live naturally in the Arboretum.

Limited funds arboretum management and level of understanding about the functions and benefits of some of the arboretum, arboretum resulted in the existence of a very minimalist. This issue will greatly affect the existence of the arboretum in the future.

The purpose of this study are aware of the economic value of the existing flora and fauna in the Dipterocarpaceae arboretum and get the benefits of environmental services for the around arboretum.

Economic valuation of the timber is done by using the market price approach. To obtain economic value of wood made a simple calculation that the total timber volume multiplied by price per unit of wood. While the economic value of air services is divided into two parts namely the absorption of carbon dioxide by the market price method and coolness by using surrogate price method.

Value of economic in Unilak dipterocarp arboretum of $R p$. $15,538,672,849.13$ consisting of timber economic value of $R p .385,843,912.00$ and the coolness of the economic value of Rp. 15,137,500,000.00 and carbon uptake value of $\mathrm{Rp}$. 15,078,937.13. The economic value of benefits in the form of services (intangible) greater (97.52\%) than the value in the form of objects (tangible) (2.48\%).
\end{abstract}

Keywords : economic value, arboretum, goods and services 


\section{PENDAHULUAN}

Arboretum sebagai salah satu contoh ekosistem yang memiliki aneka ragam flora dan fauna memerlukan pengelolaan yang baik, sehingga mampu memberikan man-faat bagi lingkungan di sekitarnya. Keanekaragaman hayati (biodiver-sity) yang ada pada kawasan Arbo-retum cukup tinggi. Hal ini dika-renakan Arboretum mempunyai ba-nyak spesies yang biasanya di-datangkan dari luar, kemudian di tanam dan dipelihara sebagai tanaman koleksi untuk berbagai keperluan kegiatan akademis, disamping spe-sies-spesies lokal yang hidup secara alami.

Sejak tahun 2001, di kawasan kampus Universitas Lancang Kuning telah dibuat arboretum dengan luasan sebesar 11,02 Hektar yang terbagi kedalam 7 blok pengelolaan (Sukma-sari, 2008). Sebagian areal arboretum tersebut mulai ditanami terutama dari jenis-jenis

Dipterocarpaceae sejak tahun 2003 dengan bibit yang didatangkan dari luar kawasan. Tujuan penanaman tersebut, selain untuk memperkaya jenis vegetasi yang ada di arboretum, juga sebagai lahan praktikum dan penelitian bagi ma-hasiswa Fakultas Kehutanan Unilak.

Pada akhir tahun 2004 terjadi perubahan kebijakan dari pihak Universitas yang akhirnya mengubah lingkungan Universitas Lancang Ku-ning menjadi lahan / kebun Sawit (Elaios quineusis). Akibat dari ke-bijakan tersebut, areal yang tadinya diperuntukkan sebagai tempat untuk melakukan praktikum bagi mahasiswa Fakultas Kehutanan dikonversi men-jadi kebun sawit (Elaios quineusis), yang mengurangi luasan Arboretum

Dipterocarpaceae. (Sukmasari, 2008).

Pilihan

kebijakan pembangunan yang melibatkan 
ekosistem apakah akan dipertahankan seperti apa adanya atau dikonversi menjadi pemanfaatan lain merupakan persoalan pembangunan yang dapat dipecahkan dengan menggunakan pendekatan valuasi ekonomi. Peran valuasi ekonomi terhadap ekosistem dan sumberdaya yang terkandung di dalamnya adalah penting dalam kebijakan pembangunan. Hilangnya ekosistem atau sumberdaya ling-kungan merupakan masalah ekonomi, karena hilangnya ekosistem berarti hilangnya kemampuan ekosistem tersebut untuk menyediakan barang dan jasa. Dalam beberapa kasus bahkan hilangnya ekosistem ini tidak dapat dikembalikan seperti sediakala (irreversible) (Adrianto, 2007).

\section{Rumusan Masalah}

Keberadaan

arboretum

Diptero-carpaceae di Universitas
Lancang Ku-ning selama ini belum mampu memberi nilai lebih bagi Unilak dan lingkungan sekitarnya. Sampai saat ini arboretum Dipterocarpaceae tersebut digunakan untuk lokasi prak-tikum beberapa mata kuliah dan penelitian mahasiswa dari Fakultas Kehutanan Unilak, sementara potensi lainnya belum dikembangkan.

Keterbatasan dana pengelolaan arboretum dan tingkat pemahaman yang kurang akan fungsi dan manfaat arboretum dari beberapa pihak, mengakibatkan keberadaan arboretum menjadi sangat minimalis. Masalah ini akan sangat berpengaruh terhadap eksistensi arboretum di masa yang akan datang.

Dari beberapa hal yang menjadi faktor tidak maksimalnya peran arboretum Dipterocarpaceae tersebut, peneliti mencoba untuk menggali potensi yang ada di arboretum 
tersebut, sehingga diharapkan dapat memberikan informasi dan gambaran dari aspek lain (ekonomi) mengenai eksistensi dari arboretum tersebut. Untuk itu penelitian ini mencoba mendapatkan nilai ekonomi dari keberadaan arboretum di kawasan lingkungan Unilak. Nilai ekonomi tersebut tidak hanya dari tegakan dan satwa yang terdapat di dalam kawasan arboretum, tetapi juga nilai jasa lingkungan dari arboretum Dipterocarpaceaea Unilak tersebut.

\section{Tujuan dan Manfaat}

Tujuan penelitian adalah mengetahui nilai ekonomi dari flora dan fauna yang ada di kawasan arboretum Unilak. Selain nilai eko-nomi flora dan fauna, penelitian ini juga bertujuan untuk adalah mendapatkan nilai manfaat jasa lingkungan dari arboretum bagi lingkungan sekitarnya.
Manfaat penelitian adalah membantu pengambil keputusan untuk menduga efisiensi ekonomi (economic efficiency) dari berbagai pemanfaatan (Competing uses) yang mungkin dilakukan terhadap eko-sistem yang ada di kawasan arboretum.

\section{METODE PENELITIAN}

Penelitian ini dilakukan selama \pm 4 bulan meliputi kegiatan persiapan, penelitian lapangan, pengolahan data dan penyusunan laporan. Sedangkan lokasi penelitian di kawasan arboretum Dipterocarpaceae Fakultas Ke-hutanan Universitas Lancang Kuning.

Bahan yang digunakan dalam penelitian seluruh jenis fauna dan flora yang terdapat di arboretum Dipterocarpaceae. Sedangkan alat yang digunakan diantaranya adalah tally sheet pengamatan, alat ukur tinggi dan diameter, alat tulis, kal-kulator dan 
kamera serta software untuk Pasar. Jenis data dan sumber pengolahan data.

Penilaian Nilai Ekonomi data dijelaskan pada tabel Kayu dilakukan dengan dibawah ini.

menggunakan pendekatan Harga

Tabel 1. Jenis data, Sumber data dan metode pengumpulan data penilaian ekonomi kayu dan hasil hutan non kayu

\begin{tabular}{ccclc}
\hline No & Uraian & Data yang diperlukan & Sumber data & $\begin{array}{c}\text { Cara pengumpulan } \\
\text { Data }\end{array}$ \\
\hline 1 & Potensi kayu & $\begin{array}{l}\text { - Volume kayu } \\
\text { - Komposisi jenis }\end{array}$ & Arboretum & $\begin{array}{l}\text { Pengamatan di lapangan dan } \\
\text { pengumpulan dokumen terkait }\end{array}$ \\
$\begin{array}{l}\text { Riap volume } \\
\text { Harga per jenis kayu } \\
\text { bulat }\end{array}$ & Harga kayu & Disperindag & Pencatatan dari dokumen \\
\hline
\end{tabular}

Untuk memperoleh nilai ekonomi

kayu dilakukan perhitungan

seder-hana yaitu volume kayu total dikali dengan harga kayu per unit. Sedangkan nilai ekonomi jasa tata udara dibagi menjadi dua bagian yaitu ; penyerapan karbondioksida dengan metode harga pasar dan kesejukan dengan menggunakan metode harga pengganti. Jenis jasa arboretum, metode penilaian, data, sumber data dan cara pengumpulan data dijelaskan pada tabel dibawah ini.

Tabel 2. Jasa hutan, metode penilaian, data yang diperlukan, sumber data dan cara pengumpulan data

\begin{tabular}{|c|c|c|c|c|c|}
\hline No & $\begin{array}{c}\text { Jasa } \\
\text { Arboretum }\end{array}$ & $\begin{array}{c}\text { Metode } \\
\text { Penilaian } \\
\end{array}$ & Data yang diperlukan & $\begin{array}{c}\text { Sumber } \\
\text { data }\end{array}$ & $\begin{array}{c}\text { Cara pengumpulan } \\
\text { data }\end{array}$ \\
\hline 1 & $\begin{array}{l}\text { Penyerapan } \\
\text { Karbondioksida }\end{array}$ & $\begin{array}{l}\text { Harga } \\
\text { Pasar }\end{array}$ & $\begin{array}{ll}\text { - Jumlah karbon } \\
\text { dalam biomass di } \\
\text { arboretum } \\
\text { - Harga karbon }\end{array}$ & $\begin{array}{l}\text { Berbagai } \\
\text { sumber }\end{array}$ & $\begin{array}{l}\text { Pencatatan dokumen } \\
\text { dan literatur }\end{array}$ \\
\hline 2 & Kesejukan & $\begin{array}{l}\text { Harga } \\
\text { Pengganti }\end{array}$ & $\begin{array}{ll}\text { - } & \text { Luas arboretum } \\
\text { Nilai kesetaraan } \\
\text { kemampuan AC } \\
\text { dan hutan alam } \\
\text { Biaya pengadaan, } \\
\text { operasional dan } \\
\text { perawatan AC }\end{array}$ & $\begin{array}{l}\text { Berbagai } \\
\text { sumber }\end{array}$ & $\begin{array}{l}\text { Pencatatan dokumen } \\
\text { dan literatur }\end{array}$ \\
\hline
\end{tabular}




\section{HASL DAN PEMBAHASAN}

Untuk memperoleh nilai ekonomi Dari hasil pengambilan jasa tata udara di kawasan data dan pengamatan di arboretum dilakukan perhitungan lapangan, diperoleh beberapa sederhana sebagai berikut data baik primer maupun

a. Nilai serapan karbondioksida sekunder yang berhubungan adalah jumlah karbon dalam biomass di arboretum dikali harga karbondioksida.

b. Nilai kesejukan adalah angka kesetaraan produksi kesejukan AC dari arboretum dikali luas arboretum dikali dengan tegakan kayu di arboretum Diptero-carpaceae Fakultas Kehutanan Uni-lak. Data tersebut antara lain adalah jenis dan volume kayu bulat serta suhu dan kelembaban di sekitar arboretum Dipterocarpaceae. biaya pengadaan, biaya Tabel berikut menjelaskan jumlah operasional dan dan potensi volume kayu bulat pemeliharaan AC. yang ada di arboretum Dipterocarpaceae.

Tabel 3. Jenis dan jumlah volume kayu yang terdapat di arboretum Dipterocarpaceae Unilak

\begin{tabular}{clrc}
\hline No. & \multicolumn{1}{c}{ Jenis Kayu } & Jumlah Pohon & Volume $(\mathbf{m} \mathbf{3})$ \\
\hline 1 & Rimba campuran & 157 & 227,39 \\
2 & Kayu Bulat Kecil & 1.482 & 332,96 \\
3 & Meranti & 2 & 2,97 \\
4 & Sengon & 11 & 17,58 \\
5 & Akasia & 12 & 13,87 \\
6 & Jelutung & 2 & 3,59 \\
7 & Prupuk & 1 & 0,89 \\
\hline \multicolumn{2}{r}{ Jumlah } & $\mathbf{1 . 6 6 7}$ & $\mathbf{5 9 8 , 3 7}$ \\
\hline
\end{tabular}

Sumber : Analisis Data Primer, 2013 
Selain itu, data tentang suhu dan Diptero-carpaceae Unilak dapat kelembaban di arboretum disajikan sebagai berikut:

Tabel 4. Suhu dan kelembaban di arboretum Dipterocarpaceae Unilak

\begin{tabular}{llllllll}
\hline \multirow{2}{*}{ No } & Waktu & \multicolumn{7}{c}{ Ulangan } \\
\cline { 3 - 8 } & \multicolumn{1}{c}{ Pengukuran } & $\mathbf{1}$ & $\mathbf{2}$ & $\mathbf{3}$ & $\mathbf{4}$ & $\mathbf{5}$ & $\mathbf{6}$ \\
\hline A. & Suhu & & & & & & \\
& a. $\quad$ Pagi & 20 & 22 & 21 & 23 & 25 & 24 \\
& b. Siang & 33 & 32 & 30 & 33 & 34 & 31 \\
& c. Sore & 29 & 30 & 28 & 30 & 31 & 29 \\
\hline & $\quad$ Rata-rata & $\mathbf{2 7}$ & $\mathbf{2 8}$ & $\mathbf{2 6}$ & $\mathbf{2 9}$ & $\mathbf{3 0}$ & $\mathbf{2 8}$ \\
\hline B. & Kelembaban & & & & & & \\
& 1. Pagi & 90 & 91 & 92 & 93 & 94 & 95 \\
& 2. Siang & 70 & 71 & 72 & 73 & 74 & 75 \\
& 3. Sore & 80 & 81 & 82 & 83 & 84 & 85 \\
\hline & Rata-rata & $\mathbf{8 0}$ & $\mathbf{8 1}$ & $\mathbf{8 2}$ & $\mathbf{8 3}$ & $\mathbf{8 4}$ & $\mathbf{8 5}$ \\
\hline
\end{tabular}

Sumber : Data Primer, 2013

Nilai Ekonomi Kayu di Arboretum Dipterocarpaceae Unilak

Secara umum, terdapat kurang lebih 76 jenis kayu di arboretum Dipterocarpaceae Fakultas Kehu-tanan Universitas Lancang Kuning. Pengukuran dimensi pohon dila-kukan hanya pada diameter $10 \mathrm{~cm}$ ke atas. Hal ini dimaksudkan agar volume kayu bulat yang diukur tersebut mempunyai potensi untuk dijual di pasaran pada masa yang akan datang. Dari 76 jenis tersebut dikelompokkan menjadi 7 kelompok seperti yang tercantum pada tabel 3. Pengelompokkan ini disesuaikan dengan patokan harga masing-masing kelompok jenis kayu ter-sebut di pasaran.

Untuk menghitung nilai ekonomi kayu dari tegakan di arboretum Dipterocarpaceae 
digunakan metode pendekatan langsung yaitu meng-gunakan nilai pasar yang berlaku. Untuk memperoleh harga pasar digunakan daftar harga kayu bulat yang bersumber dari Peraturan Menteri Perdagangan Nomor: 22/M-DAG/PER/4/2012 tentang Penetapan Harga Patokan Hasil Hutan Untuk Penghitungan Provisi Sumber Daya Hutan. Sedangkan data biaya pemanenan kayu bulat bervariasi tergan-tung jumlah hasil produksinya per hektar. Diperoleh rata-rata kumulatif biaya tebang ${ }^{1}$ sebesar Rp 16.601,12,- per $\mathrm{m}^{3}$, dan biaya rata-rata angkutan menuju lokasi konsumen rata-rata sebesar Rp 70.716,70,- per $\mathrm{m}^{3}$. Khusus untuk jenis sengon dan dan akasia, harga kayu yang ada dalam satuan ton, sehingga perlu dilakukan konversi. Menurut Rochmayanto (2011), angka konversi mangium adalah $1 \mathrm{~m}^{3}=$ 0,86 ton. Dari in-formasi tersebut, maka volume kayu sengon dari $17,58 \mathrm{~m}^{3}$ menjadi 15,12 ton dan volume akasia dari $13,87 \mathrm{~m}^{3}$ menjadi 11,93 ton.

Dari hasil penelitian, diperoleh volume kayu yang terdapat di arboretum

Dipterocarpaceae Unilak tersebut sebesar 598,37 $\mathrm{m}^{3}$. Volume kayu tersebut akan menghasilkan nilai ekonomi kayu bulat sebesar Rp. 385.843.912,-. Nilai kayu merupa-kan nilai produktivitas yang dimiliki oleh arboretum Dipterocarpaceae Unilak yang belum pernah dihitung. Nilai ekonomi kayu tersebut merupakan masukan bagi Unilak tentang nilai potensi aset yang dimiliki arboretum dan akan terus berkembang. Nilai kayu dari arboretum ini akan dapat ditingkatkan lagi bila pohon-pohon yang dikem-

1. Penelitian yang berjudul Analisis Pungutan Rente Ekonomi Kayu Bulat Hutan Tanaman Industri di Indonesia oleh Transtoto Handhardari dkk. 
bangkan di arboretum mempunyai nilai ekonomi yang tinggi.

Nilai ekonomi tersebut, secara potensi masih bisa meningkat, karena tidak semua jenis pohon hanya dimanfaatkan kayunya secara lang-sung, akan tetapi ada beberapa jenis pohon seperti gaharu dan jelutung yang jika tidak diambil kayunya, tetapi dibudidayakan untuk mendapatkan gubal gaharunya dan getah jelutung, maka nilai kayu tersebut secara ekonomis akan lebih tinggi dari saat ini. Selain gaharu dan jelutung, juga terdapat beberapa jenis tumbuhan yang beberapa bagiannya bisa dimanfaatkan untuk keperluan rumah tangga dalam skala ekonomis, seperti rotan, bambu dan sebagainya.

Nilai Ekonomi Kesejukan di Arboretum Unilak

Nilai kesejukan diperoleh dengan menggunakan teknik analisis biaya, yaitu pendekatan menilai manfaat ekonomi yang hilang karena kerusakan lingkungan akibat kegi-atan ekonomi adalah mengukur biaya pengganti jasa lingkungan yang dirusak orang. Dalam hal ini adalah pemakaian AC sebagai ganti pohon untuk maksud memperoleh kese-jukan udara. Penilaian yang dila-kukan hanya berdasarkan pada po-tensi hutan yang ada di Arboretum Dipterocarpaceae Unilak.

Untuk mengganti hilangnya kesejukan akibat ditebangnya pohon-pohon yang ada maka diperlukan biaya pengadaan AC, perawatan dan pemeliharaan, dengan demikian nilai kesejukan adalah Rp. 15.137.750.000,- per tahun.

Nilai kesejukan tersebut memang terasa sangat tinggi dan masih jauh dari kenyataan yang sebenarnya dimana manfaat kesejukan itu dirasakan. Sebenarnya manfaat yang lebih 
nyata bisa dilakukan dengan menggunakan metode biaya perja-lanan, namun tidak dilakukan dalam penelitian ini.

Dari hasil penelitian Asiani (2000) dalam Roslinda (2002), eko-sistem di bawah pepohonan lebih rendah suhunya $3-5^{\circ} \mathrm{C}$ dan kelem-baban di dalam ekosisitem hutan lebih tinggi $20-30 \%$. Sebagai perbandingan dari data suhu yang tercatat di arboretum Dipterocar-paceae

Unilak mencapai rata-rata 27 sd $30^{\circ}$ Celcius. Sementara itu jika dibandingkan suhu udara di Kota Pekanbaru saat ini mencapai hingga $35 \circ \mathrm{C}$, terlihat bahwa keberadaan ar-boretum

Dipterocarpaceae Unilak memiliki manfaat yang cukup tinggi dalam menjaga keseimbangan suhu di sekitar kawasan kampus Unilak. Keadaan ini dapat menekan kebutuhan AC serta energi. Biaya yang diperlukan untuk mendinginkan ruangan menjadi lebih rendah, jika kawasan di sekitar kampus sudah sejuk dan nyaman. Besarnya biaya tersebut merupakan sebuah nilai kesejukan dari arboretum Dipterocarpaceae Unilak.

Nilai kesejukan yang diperoleh dari arboretum Dipterocarpaceae Unilak merupakan nilai pembelian kesejukan yang selama ini dilakukan oleh masyarakat perkotaan. Dengan diketahuinya nilai kesejukan ini, diharapkan pihak pengguna (masya-rakat kampus dan warga sekitar kampus) akan lebih menghargai ar-tinya keberadaan sebatang pohon bagi kehidupan manusia. Karena lingkungan yang sejuk akan mem-berikan rasa nyaman, sehat dan indah bagi masyarakat.

\section{Nilai Ekonomi Serapan Karbon di Arboretum Dipterocarpaceae Uni-lak}

Besarnya kemampuan hutan sebagai gudang karbon dicerminkan oleh besarnya 
volume biomas dari hutan tersebut. Perhitungan nilai hutan sebagai gudang karbon yang ada pada biomas hutan tersebut. Berdasarkan pada beberapa informasi nilai karbon untuk seluruh areal pada setiap tahunnya digunakan standar nilai sebagai berikut :

a. Satu (1) ton karbon bernilai US\$ 10 (ITTO \& FRIM, 1994 dalam Roslinda, 2002)

b. Berat jenis kayu dari hutan tropika alam adaah rata-rata $560 \mathrm{~kg} / \mathrm{m}^{3}$ (ITTO \& FRIM, 1994, digunakan World bank, 1992 dalam Roslinda, 2002)

C. Berat karbon dalam $1 \mathrm{~kg}$ kayu kering adalah sekitar 0,5 kg (ITTO \& FRIM, 1994 dalam Roslinda, 2002)

d. Satu $\mathrm{m}^{3}$ biomass $=0,28$ ton karbon (Roslan \& Woon, 1993 dalam Roslinda, 2002).

Nilai hutan sebagai gudang karbon ini diperhitungkan untuk biomas yang masih utuh (belum membusuk, terurai). Karena arbore-tum Dipterocarpaceae Unilak me-rupakan areal yang kayunya tidak ditebang maka diasumsikan biomas kayu tetap berada di hutan.

Kondisi arboretum Dipterocarpaceae Unilak diasum-sikan sebagai hutan tanaman, dimana penyerapan karbon pada HTI Acacia mangium adalah 215 ton/ha (Kuusi-palo, 1995 dalam Roslinda, 2002). Potensi kayu yang ada di arboretum Dipterocarpaceae Unilak adalah 598,37 $\mathrm{m}^{3}$, maka kandungan karbon yang terdapat di arboretum Dipte-rocarpaceae Unilak adalah 167,54 ton. Dengan demikian nilai serapan karbon yang dihasilkan adalah sebe-sar Rp. 15.078.937,13.

\section{Nilai Ekonomi Total Arboretum Dipterocapceae Unilak}

Nilai ekonomi total arboretum Dipterocarpaceae Unilak merupakan jumlah dari 
nilai guna langsung dan nilai guna arbore-tum

Dipterocarpaceae tidak langsung arboretum Unilak secara lengkap dapat Dipterocarpaceae. Hasil yang dilihat pada tabel 5.

diper-oleh dari nilai ekonomi total

Tabel 5. Nilai ekonomi total arboretum Dipterocarpaceae Unilak

\begin{tabular}{crrr}
\hline No & \multicolumn{1}{c}{ Jenis Nilai Ekonomi } & Nilai Total (Rp) & Persentase (\%) \\
\hline 1 & Nilai ekonomi kayu & $385.843 .912,00$ & 2,48 \\
2 & Nilai ekonomi kesejukan & $15.137 .750 .000,00$ & 97,42 \\
\multirow{2}{*}{3} & $\begin{array}{l}\text { Nilai ekonomi serapan } \\
\text { karbon }\end{array}$ & $15.078 .937,13$ & 0,10 \\
\hline \multicolumn{2}{c}{ Jumlah } & $\mathbf{1 5 . 5 3 8 . 6 7 2 . 8 4 9 , 1 3}$ & $\mathbf{1 0 0 , 0 0}$
\end{tabular}

Sumber : Analisis Data Primer, 2013

Nilai ekonomi total arboretum Dipterocarpaceae Unilak ada-lah sebesar

Rp. 15.538.672.849,13, dimana $97,52 \%$ merupakan nilai penggunaan tak langsung berupa jasa lingkungan hutan, dan $2,48 \%$ merupakan nilai biomasa kayu. Dari dua nilai terseebut tampak bahwa nilai hutan yang berupa manfaat jasa (intangible) lebih besar daripada nilai berupa benda (tangible), oleh karenanya ekosistem hutan sebagai kesatuan yang utuh harus

diperta-hankan kelestariannya. Begitu juga dengan arboretum Dipterocarpaceae Unilak harus tetap dipertahankan keberadaannya karena memiliki nilai ekonomi yang tinggi. Selain itu sudah saatnya paradigma perhatian pengelolaan fungsi hutan yang lebih mengutamakan manfaat tangible diubah, paling tidak memberikan perhatian yang seimbang diantara kedua fungsi hutan tersebut. Dan untuk selanjutnya disarankan bahwa 
pengelolaan hutan lebih menguta-makan manfaat intangible daripada tangible secara proporsional karena terbukti manfaat intangible lebih besar.

Besarnya manfaat intangible hutan seperti jasa kesejukan akan lebih terasa manfaatnya pada kawasan di sekitar arboretum

Dipterocarpaceae Unilak, karena dapat menjadi daerah resapan air, yang sangat bermanfaat jika musim hujan dan pada saat musim kemarau mampu memberikan keseimbangan dengan lingkungan sekitarnya dalam bentuk kontribusi berupa kelem-baban dan kesejukan. Begitu juga manfaat intangible lain seperti nilai serapan karbon, di arboretum Dipte-rocarpaceae Unilak, walaupun ha-nya mencapai $0,10 \%$, tetapi di kawasan konsesi PT. Inhutani Unit I, Labanan, Berau Kalimantan Timur mencapai $89 \%$ dari nilai total (Kim, 2001 dalam Roslinda, 2002). Ini di-sebabkan kondisi pada hutan tropika telah mencapai klimaks, mengandung karbon yang maksimum yaitu tingkat karbon yang paling tinggi dan dalam kondisi yang seimbang antara yang keluar dan yang masuk, sehingga berperan terhadap stabilitas iklim secara konstan dan lestari disamping macam pendekatan/ metode yang digunakan dalam penghitungan nilai karbon tersebut.

\section{KESIMPULAN DAN SARAN}

Nilai ekonomi arboretum Dipterocarpaceae Unilak mencapai Rp. 15.538.672.849,13 yang terdiri dari nilai ekonomi kayu sebesar Rp. 385.843.912,00 dan nilai ekonomi kesejukan sebesar Rp. 15.137.500.000,00 serta nilai serapan karbon sebesar $R p$. 15.078.937,13. Nilai ekonomi yang berupa manfaat jasa 
(intangible) lebih besar $(97,52 \%)$ daripada nilai berupa benda (tangible) (2,48\%).

Pengukuran nilai ekonomi kawasan arboretum Dipterocarpaceae Unilak dapat dilakukan dengan teknik pendekatan dan metode yang lain, sebagai pemban-ding nilai ekonomi yang ada teru-tama untuk beberapa nilai, seperti nilai resapan air, nilai rekreasi dan nilai sewa lahan. Pengukuran nilai ekonomi kawasan arboretum Dipte-rocarpaceae perlu dikembangkan agar mampu memberikan kontribusi positif bagi masyarakat yang tinggal di sekitarnya.

\section{DAFTAR PUSTAKA}

Adrianto, Luky., Akhmad Fahrudin, Yudi Wahyudin. 2007. Kon-sepsi Valuasi Ekonomi Sum-berdaya Alam dan Ling-kungan. Modul. Pusat Kajian Sumberdaya Pesisir dan Laut-an Institut Pertanian Bogor. Bogor.
Handhardari, T. dkk. 2005. Analisis Pungutan Rente Ekonomi Ka-yu Bulat Hutan Tanaman In-dustri di Indonesia. Jurnal Puslitsosekhut Vol. 6 No.2 tahun 2005 No ISBN 18298129 (www.puslitsosekhut. web.id)

Rochmayanto, Yanto. 2011. Harga kayu pulp hutan rakyat bisakah ditingkatkan. (http://www.rimbawan.or.id/2 011/09 diunduh tanggal 10 Juli 2013)

Roslinda, Emi. 2002. Nilai Ekonomi Hutan Pendidikan Gunung Walat dan Kontribusinya Terhadap Masyarakat Sekitar. Tesis. Program Pascasarjana Institut Pertanian Bogor. Bogor.

Sukmasari. 2008. Laju Pertumbuhan Permudaan meranti Merah (Shorea leprosula miq) di Arboretum Dipterocarpaceae Fakultas Kehutanan Unilak. Skripsi. Fakultas Kehutanan Universitas Lancang Kuning. Pekanbaru. 